$\infty$

0

0

م

O

1

$\infty$

드

3

0

$\infty$

0

0

$\bar{\alpha}$

-

U

F

is

U

$\frac{1}{\alpha}$

$\omega$

0

0

E

$\infty$

山 


\title{
PROSPERIDADE, CONTESTAÇÃO E TECNOCRACIA: O PENSAMENTO ROGERIANO EM SEU CONTEXTO DE GESTAC̣ÃO
}

\author{
Prosperity, contestation and technocracy: the rogerian thought in its context of gestation
}

Prosperidad, contestación y tecnocracia: el pensamiento rogeriano en su contexto de gestación

\author{
Francisco Pablo Huascar Aragão Pinheiro \\ JACQUELINE DE Oliveira MOREIRA \\ ANDRÉa MARIS CAMPOS GUERRA
}

EMANuel Meireles Vieira

\begin{abstract}
Resumo: O artigo pretende problematizar as condições culturais a partir das quais foi construído o pensamento de Carl Rogers. Discutem-se acontecimentos ocorridos na sociedade estadunidense a partir do início da segunda guerra mundial até o fim da década de 1970. Entende-se que a guerra representou uma oportunidade para que os Estados Unidos iniciassem um ciclo economicamente virtuoso. Havia, nesse período, uma forte sensação de prosperidade para parte de sua população associada ao advento de uma classe média com tendências conservadoras. Paralelamente, surgiram movimentos contestatórios de populações historicamente marginalizadas que buscavam direitos civis e questionavam os modos de organização social e cultural vigentes. A partir disto, desenvolveu-se uma psicologia mais prática e que fugia de referenciais tecnocráticos de produção e validação de conhecimento. Dentro desse contexto cultural, indica-se que Rogers respondia, entre outros, aos temas: autenticidade atrelada à busca de tornar-se pessoa; tecnocracia como elemento a ser questionado na vida e na produção de conhecimento; e, por fim, cuidado de si vinculado ao sério risco de se cair num modo narcísico de existência.
\end{abstract}

Palavras-chave: Abordagem Centrada na Pessoa; Contexto Cultural Estadunidense; Psicologia Humanista

\begin{abstract}
The paper aims to debate the cultural conditions from which Carl Rogers' thinking was created. Events that happened in american society from the beginning of second World War until the end of 1970's are discussed. It is understood that the war represented an opportunity for the United States to start a new economically virtuous cicle. There was, during this time, a strong feeling of prosperity for part of its population combined with the advent of a conservative middle class. In parallel, contestatory movements of historically marginalized populations emerged. These movements sought civil rights and questioned the ways of social and cultural organization in force. Therefore, it was developed a more practical psychology which evaded itself from technocratic references of production and validation of knowledge. Within this cultural context, it is indicated that Rogers responded, among others, to the themes: authenticity tied to the quest to become a person; technocracy as an element to be questioned in life and in the production of knowledge; And, finally, self-care linked to the serious risk of falling into a narcissistic way of existence.

Keywords: Person-Centered Approach; American Cultural Context; Humanistic Psychology.

Resumen: El artículo pretende problematizar las condiciones culturales a partir de las cuales se construyó el pensamiento de Carl Rogers. Se discuten acontecimientos ocurridos en la sociedad estadounidense a partir del inicio de la segunda guerra mundial hasta el final de la década de 1970. Se entiende que la guerra representó una oportunidad para que los Estados Unidos iniciasen un ciclo económicamente virtuoso. En ese período, había una fuerte sensación de prosperidad para parte de su población asociada al advenimiento de una clase media con tendencias conservadoras. Paralelamente, surgieron movimientos contestatarios de poblaciones históricamente marginadas que buscaban derechos civiles y cuestionaban los modos de organización social y cultural vigentes. A partir de esto, se desarrolló una psicología más práctica y que huía de referenciales tecnocráticos de producción y validación de conocimiento.Dentro de ese contexto cultural, se indica que Rogers respondía, entre otros, a los temas: autenticidad ligada a la búsqueda de convertirse en persona; tecnocracia como elemento a ser cuestionado en la vida y en la producción de conocimiento; y, por fin, cuidado de sí vinculado al serio riesgo de caerse en un modo narcisista de existencia.
\end{abstract}

Palabras-clave: Enfoque Centrado en la Persona; Contexto Cultural Estadonidense; Psicología Humanista.

\section{Introdução}

A Psicologia é um conhecimento histórico. Isso implica em dizer que, mais do que nos determos à sucessão cronológica e epistemológica de ideias, cabe-nos reconhecer que a própria concepção de fenômeno psíquico não pode ser compreendida adequadamente sem que se analisem os fenômenos históricos que a tornaram possível. Neste sentido, para que se compreenda a gênese de algumas ideias psicológicas, é necessário que se entendam suas condições de possibilidade, ou seja, que fenômenos sociais as tornaram possíveis em uma época e não em outra. 
Como inspiração para o tipo de questionamento lançado acima, tomaremos Figueiredo (1992), que nos aponta que nem sempre houve uma noção de subjetividade privatizada e que, portanto, aquilo que naturalizamos indivíduo é uma invenção moderna. O referido autor faz alusão a uma série de mudanças que se sucederam na sociedade ocidental após a Idade Média e que tornaram possível a concepção de que cada pessoa é única e, assim, dotada de singularidade.

Nesse lastro, a despeito dos muitos textos que tratam de uma história da Abordagem Centrada na Pessoa (ACP), não se encontra um debate mais consistente em torno do ambiente histórico e cultural com o qual esta teoria da psicologia dialoga em sua gênese (Cury, 1987; Rogers \& Russell, 2002; Kirschenbaum, 2007; Moreira, 2010; Castelo Branco, 2010). Para que possamos nos lançar ao desafio de responder a esse tipo de questão, interessa-nos analisar o período compreendido entre os anos 1940 e o fim da década de 1970, nos Estados Unidos quanto aos eventos ocorridos naquela sociedade e de que modo eles ajudaram a construir uma concepção específica de Psicologia e, ainda mais especificamente, a teoria de Carl Rogers. A questão que nos guiará será: com que acontecimentos históricos, dentro e fora do campo da Psicologia, Rogers dialogava enquanto produzia sua obra? Dito de outro modo: a quais provocações, de seu contexto cultural, Rogers estaria respondendo?

Inicialmente, discorrer-se-á sobre o contexto cultural estadunidense compreendido entre as décadas de 1940 e 1970, uma vez que foi esse período em que se desenvolveu mais fortemente a obra rogeriana. Em seguida, discutir-se-á o contexto de desenvolvimento da Psicologia estadunidense e sua relação com a emergência da obra rogeriana. Finalmente, será apresentada uma reflexão sobre de que modo os valores e questões emergentes no período analisado se relacionam com temáticas abordadas por Rogers.

\section{A Segunda Guerra Mundial nos Estados Unidos: Prosperidade num Mundo em Ruínas}

Segundo Foertsch (2008), os anos 1940 começaram para o mundo em 1939. Como é sabido, em primeiro de setembro daquele ano, a Alemanha, violando um pacto de não agressão, invadiu a Polônia e, então, se iniciou a Segunda Guerra Mundial. Inicialmente, o conflito não contou com a participação dos Estados Unidos, que faziam negócios com ambos os lados em guerra e, assim, aumentavam os lucros de suas indústrias. A decisão de tomar partido no embate só ocorreu após o ataque japonês à base de Pearl Harbor (Foertsch, 2008).

A decisão estadunidense envolveu toda a população e movimentou a economia, de modo que setores tradicionalmente marginalizados da atividade produtiva, como “(...) mulheres de classe média, brancos pobres, americanos de cor, e os deficientes físicos (...) tiveram oportunidades de trabalho significativas e lucrativas" (Foertsch, 2008, p. 10, tradução nossa). Isso significou para os Estados Unidos, além do risco à vida dos soldados, uma curiosa junção de sacrifício por parte de civis (com racionamentos de comida, petróleo e outros bens materiais básicos) e abertura de possibilidades de inclusão produtiva.

Com o fim do conflito, os Estados Unidos estavam numa situação absolutamente diversa da Europa (Hobsbawm, 1994/2004). Além da expansão da indústria, o Servicemen's readjustment act, também conhecido como GI Bills, um fundo a partir do qual o governo estadunidense facilitou o acesso de veteranos de guerra a moradia, crédito, instituições de ensino, entre outros serviços e bens de consumo, colaborou no processo de formação e fortalecimento da classe média americana (Foersctch, 2008), identificada por Reisman (1950/1971) como "(...) o burocrata, o empregado assalariado no domínio dos negócios”.

Os EUA assumiram a posição de representantes de um bloco ocidental hegemônico em defesa de uma sociedade tida como livre, contra a expansão do comunismo, representada por outra grande potência fortalecida no conflito: a União Soviética - URSS (Foertsch, 2008). Esta situação, segundo Hobsbawm (1994/2004), marcou o início de um segundo ciclo no século XX, situado entre 1945 e 1973, de grande força do capitalismo, de prosperidade para os países tidos como desenvolvidos e grande tensão mundial: a Guerra Fria. Tamanha prosperidade nos EUA resultou num clima extremamente conservador - no sentido de manutenção do status quo - naquele país durante o fim da década de 1940 e os anos 1950, de tal forma que, fosse membro ou simpatizante dos partidos Democrata ou Republicano, havia um consenso de uma ameaça constante no ar (Halliwell, 2007). Não por acaso, um dos grandes temas era o da autenticidade. Afinal, se o risco de assunção do comunismo era tão forte - e ele poderia estar em qualquer lugar — , como saber em quem confiar?

Há que se ressaltar que, embora tenha havido um enorme incremento no consumo e na classe média americana, este fenômeno não aconteceu de forma igualitária e universal. Populações bastante significativas de setores historicamente marginalizados, como jovens, negros, mulheres e homossexuais, viram-se sem o devido reconhecimento coletivo (Halliwel, 2007). As mulheres, por exemplo, após a guerra, receberam enorme pressão para voltar aos seus postos de donas de casa. O questionamento do modelo de sociedade que se desenvolvia, porém, tinha pouco espaço, pois os intelectuais eram associados pela mídia ao grande inimigo comunista do período da Guerra Fria. Segundo Halliwell (2007), no âmbito da classe média branca americana, raramente se questionava; consumia-se. Isto caracterizaria a década de 1950 como uma era de anti-intelectualismo, com enorme importância dada ao mercado, embora, conforme se verá mais adiante, houvesse interrogações e tentativas de explicação sobre o que ocorria naquele contexto - algo que viria a se consolidar na década 
seguinte. Riesman (1950/1971), por exemplo, estabelece interessante reflexão sobre o período em questão, e entende que o tipo de sociedade que se apresentava àquele tempo era alterdirigida, em contraposição às mais tradicionais, tidas por ele como traditivas, e as de transição, por ele definidas como introdirigidas. As sociedades traditivas seriam aquelas que preservariam a estabilidade e envolveriam o medo da vergonha, com referencial coletivista. As sociedades intradirigidas teriam como marca a expansão individual e a mobilidade pessoal, portanto com mais instabilidade e uma tensão entre o indivíduo e a tradição introjetada, resultando em culpa. Na alterdireção, por sua vez, prevaleceria o tempo presente, com menor peso da tradição e maior velocidade na familiarização do estranho - o consumo imediato da mais absoluta novidade, gerador de ansiedade.

Ansiedade pelo ajustamento, pela necessidade de conseguir acompanhar um grupo de referência, cada vez mais ditado pelos meios de comunicação de massa, na busca de referências abaladas por transformações tão profundas no modo de organização social. Afinal, a urbanização acelerada dos países desenvolvidos, a prosperidade econômica, a sinalização de mudanças nas relações raciais, o aumento do poder da mídia (Hobsbawm, 1994/2004), entre outras, são alterações significativas na configuração de uma sociedade.

Para Riesman (1950/1971), no período em tela, a necessidade de saber quem se é dá lugar à de se sentir aceito num grupo que se tem como referência para valores, de modo que esta é inversamente proporcional àquela. Tal característica incide, por exemplo, sobre educação e trabalho, de modo que é a capacidade de se relacionar com pessoas e se adequar a elas que ganha relevo nestes dois âmbitos.

Riesman ainda se questiona sobre o espaço existente para a autonomia diante da necessidade de ajustamento ao grupo. Afinal, as instituições que tradicionalmente moldavam estes limites já estavam àquela época em franca decadência. Assim, Riesman (1950/1971) identificava a necessidade de apontar caminhos utópicos rumo à autonomia. Para o referido autor, era preciso criar uma linha tênue entre a convivência com o coletivo e a possibilidade de reconhecimento das aspirações individuais.

\section{Os Anos de 1960: Prosperidade e Questionamento no Mesmo Cenário}

Paralelamente ao crescimento econômico, ocorreu nos EUA um processo de luta pelos direitos civis que evidenciou que a prosperidade não atingia as populações mencionadas acima. Se os EUA tinham como bandeira a liberdade contra uma ditadura comunista, esse valor não se aplicava a todos os seus habitantes. Até 1948, por exemplo, as forças armadas americanas eram segregadas a partir da cor da pele das pessoas que delas faziam parte (Farber \& Bailey, 2001; Foertsch, 2008).

Outra demonstração de segregação racial dizia respeito ao fato de negros não terem os mesmos direitos civis que brancos até então. Assim, eles não podiam votar nem frequentar as mesmas escolas que os brancos. A situação era mais tensa no Sul do país, tido como mais atrasado economicamente e com uma presença maciça de população afrodescendente, além de uma elite extremamente conservadora quanto à manutenção de seus privilégios (Monteith, 2008). Foi nessa região dos EUA que se iniciou o movimento sitin, em que estudantes negros passaram a ocupar espaços antes destinados apenas a brancos. Foram crescentes e variadas as formas de protesto por todo o país, que resultaram na aprovação de uma série de direitos civis, em 1965, pelo Senado americano, conhecida como Lei dos Direitos Civis (Civil Right Acts).

A incidência da Lei dos Direitos Civis não atingiu apenas a discriminação racial, mas também questões de gênero e quaisquer outros tipos de discriminação em locais e instituições públicas ou privadas. Isto não significou, porém, o fim da segregação, senão que abriu o caminho para muitas outras lutas e conquistas que viriam (Brownell, 2011). Isto se deu através de uma série de ações estatais de estímulo à criação de novas oportunidades para as referidas populações, como a Comissão para Igualdade de Oportunidade de Emprego - Equal Employment Opportunity Comission (Farber \& Bailey, 2001).

Uma das reverberações das lutas pelos direitos civis foi a "nova" esquerda. Nova, porque não se associava necessariamente a ideias marxistas, mas se baseava na crença em uma sociedade fundamentada no amor, na fraternidade e na paz (Farber \& Bailey, 2001). Isto moldava os diversos movimentos da nova esquerda - um "movimento" fundamentalmente levado a cabo por jovens universitários que sonhavam com uma nova sociedade.

Vários autores (Gair, 2007; Suri, 2009; Brownell, 2011) são unânimes em entender que a nova esquerda é fruto da prosperidade econômica dos EUA, pois os jovens viveram tempos de muito menos trabalho e mais acesso a bens de consumo e educação do que seus pais, remanescentes da crise econômica de 1929. Neste sentido, para Gair (2007), trata-se, em parte, de conflito geracional. O lugar de protagonista assumido pela juventude pode ser entendido na medida em que os arranjos familiares no pós-guerra mudaram drasticamente. A tradição (Riesman, 1950/1971) dá lugar ao novo e, mesmo a atitude pública perante o comportamento sexual, sofreu mudanças bastante profundas, de modo que o sexo antes do casamento, a união entre homossexuais, a possibilidade de a mulher sair da casa antes de casar, entre outros, passaram a ser comportamentos aceitáveis.

Segundo Hobsbawm (1994/2004), a radicalização política dos anos 1960 pertencia aos jovens da nova esquerda, que se recusavam a reconhecer o lugar da autoridade adulta. Ainda de acordo com Hobsbawm, a ascensão da juventude na década de 1960 trazia três novidades, a saber: a juventude não era mais um estágio de 
passagem, mas um ideal a ser atingido; tornouse um comportamento dominante nas economias de mercado desenvolvidas; criou-se um mercado consumidor jovem, pois a cultura da juventude se internacionalizou através de vários bens de consumo cultural, como roupas, revistas e discos.

Uma variação peculiar do novo cenário era a contracultura, que se caracterizava pela busca de modos alternativos à cultura jovem do consumo de classe média. Foram várias as comunidades alternativas criadas em todo o território estadunidense em que se tentava ter uma vida própria, fora dos padrões consumistas em que se modelava a sociedade dos EUA, vivendo coletiva e cooperativamente (Brownell, 2011). Sem crer nas instituições de então, os jovens da contracultura viam nas relações pessoais, e não nas formais, a origem das mudanças em seu país (Hobsbawm, 1994/2004). Para Gair (2007), se os protestos contra as guerras e o movimento dos direitos civis tinham como interesse mudar o mundo, o uso de drogas ilícitas, especialmente o LSD, “(...) oferecia a promessa de transcendência do mundo" (p. 135, tradução nossa). Brownell (2011), por seu turno, considera que o LSD funcionava como meio para expansão do eu - a grande busca da época - e condição para desenvolvimento de um senso de comunidade.

Campos (2006) atesta que os jovens da contracultura contestavam um estilo de sociedade que privilegiava “(...) aspectos técnico-racionais em detrimento dos sociais e humanos, reforçando uma tendência crescente para a burocratização da vida social" (p. 242). Reconhecia-se, portanto, que o modo vigente, e tido por muitos como tão próspero, era insuficiente na busca sobre o sentido da própria existência, sem uma clara separação entre as esferas política e pessoal. As críticas ao modelo consumista não significavam, porém, uma ruptura com valores muito caros à cultura americana, “(...) como a liberdade individual de escolha, como alternativas a um capitalismo corporativo que eles percebiam corromper ideais americanos" (Gair, 2007, p. 26).

Tratava-se de uma busca por autenticidade, por novos modos de vida que, consoante Suri (2009), encontrava suas raízes no movimento beat que dominou a arte estadunidense da década de 1950, tendo como ícones artistas como o escritor Jack Kerouac e o poeta Allen Ginsberg, entre outros. Esses artistas buscavam, através dos vários de tipos de expressão, algo mais natural, em oposição ao mundo pré-fabricado da indústria. Era um questionamento sobre o sentido da vida boa. Roszak entendia que a juventude envolvida na contracultura se levantava contra a tecnocracia, “(...) aquela sociedade na qual os governantes justificamse invocando especialistas técnicos, que, por sua vez, justificam-se invocando formas científicas de conhecimento. E além da autoridade da ciência não cabe recurso algum" (Roszak, 1968/1972, p. 21). Roszak ainda considerava a tecnocracia como totalitária, uma vez que a palavra final é a técnica, revestida de uma pretensa neutralidade conferida à ciência e à razão. A metáfora que melhor representa o modelo de sociedade contra o qual a contracultura se insurge é o da bomba atômica, que demonstra todo o compromisso do industrialismo maduro com o genocídio, de modo que, em nome do avanço tecnocrático, verdadeiros absurdos eram cometidos.

Não por acaso, os jovens da contracultura, sem saber definir muito bem o que queriam, tinham clareza do modelo que não gostariam de adotar como filosofia de vida. Por isso, entendiam que a mudança a ser conduzida dizia respeito à consciência, e não à ideologia, de tal forma que “(...) a construção da boa sociedade não é uma tarefa primordialmente social, e sim psíquica" (Roszak, 1968/1972, p. 61). Era, portanto, o envolvimento pessoal, o sentido da experiência para si, o que importava. Destarte, entendia-se que, pelo apego a ideologias, especialmente à tecnocracia, havia-se esquecido da dimensão humana, pessoal, em última instância do envolvimento da pessoa em ação. Inevitavelmente, perguntava-se sobre o que é ser uma pessoa e quais os elementos intrinsecamente humanos. Como consequência, “(...) a consciência de classe cede lugar, como princípio generativo à (...) consciência da consciência" (Roszak, 1968/1972, p. 72, grifo do autor). Valorizava-se, assim, um campo místico, uma sabedoria pré-reflexiva, oriunda da expressão imediata da experiência do aqui-e-agora.

Tratava-se, portanto, de um misticismo que encontrava no corpo uma realidade em que se amparasse e fizesse sentido, que rejeitava a ciência, o academicismo, a tecnocracia e todas as formas que tentassem tornar objetivas experiências humanas que não poderiam ser assim reduzidas. Afinal, para Roszak (1968/1972), a ciência elimina o prazer e a relação direta com o mundo, ou seja, elimina a pessoa como totalidade. Ainda segundo o aludido autor, porém, a contracultura corria o risco de sucumbir a dois perigos: não aprofundar seu relacionamento com os menos favorecidos economicamente; e se tornar mais um espetáculo a entreter uma sociedade consumista.

\section{A Retomada de uma Onda Conservadora em Meio a Desejos de Mudança}

Se as duas décadas anteriores foram de prosperidade financeira para o mundo desenvolvido, foi na década de 1970 que o mundo vivenciou uma crise que se estenderia durante mais de 20 anos. Períodos sucessivos de recessão econômica tomavam conta do planeta em seus diversos continentes - com exceção de parte da Ásia (Hobsbawm, 1994/2004). Os Estados nacionais, propulsores e organizadores do que Hobsbawn (1994/2004), em referência ao período do pósguerra, compreende como Era de Ouro, haviam perdido poder de controle e planejamento da economia, de tal forma que as grandes companhias, com sedes em vários locais do mundo, lucravam cada vez mais, e o aumento das desigualdades também seguia esta proporção. Houve um severo embate entre os economistas que apostavam no Estado de Bem-Estar Social, surgido no pós-guerra, e os neoliberais, que acreditavam que o mercado 
se regulava a partir da livre concorrência e sem a intervenção estatal (Hobsbawm, 1994/2004).

O pleno emprego rapidamente já não era mais uma realidade. A ideia era aprofundar a lógica de fazer mais e ganhar mais com menos, a partir da aceleração da substituição do trabalho humano pelo uso de máquinas através do avanço da informática e da robótica. Isto tirou força do movimento trabalhista e fortaleceu grupos xenófobos, bem como movimentos ligados à causa ecológica (Hobsbawm, 1994/2004).

O conservadorismo político também ocorreu num plano cultural mais amplo. Líderes fundamentalistas ganharam espaço na mídia e arrebanharam cada vez mais adeptos a suas seitas. Era comum o aumento de venda de publicações vinculadas a visões religiosas, além de emissoras de rádio e televisão evangélicas (Suri, 2009; Kaufman, 2009). Havia uma tensa convivência entre manifestações cada vez mais frequentes por direitos de minorias historicamente desprezadas e grupos conservadores.

De acordo com Kaufman (2009), há entendimentos de que a década de 1970 funcionou como uma individualização da busca pela compreensão de si mesmo que tanto marcou os grupos da contracultura. A autodescoberta, a autorrealização e afins podem ter tido como resultado um indivíduo autocentrado. Uma experiência que sofreu as mudanças citadas por Kaufman é a de ver um filme. Nos cinemas, até a década 1970, isso ocorria coletivamente. Com os aparelhos de videocassete, foi possível realizar esta mesma atividade sozinho, no conforto do seu lar.

Essa característica individualista forneceu a Lasch (1979/1991) a condição de qualificar a década em questão como uma época da cultura do narcisismo. Para Lasch (1979/1991), havia uma crise espiritual nos anos 1970 no sentido de que se enfatizava muito a vida presente em detrimento de um senso de continuidade histórica. Assim, o sonho de transformar o mundo deu lugar à busca pela sobrevivência física e psíquica.

A fome das pessoas naquele contexto, de acordo com Lasch (1979/1991), era de “(...) sentimento, ilusão momentânea, de bem-estar pessoal, saúde e segurança psicológica" (p. 7, tradução nossa). Para Lasch, segundo Wanderley (1999), a burocratização, a sobrevalorização da imagem, as ideologias terapêuticas, a racionalização da vida interior, o culto ao consumismo e as mudanças na vida familiar - acontecimentos que se fortaleceram no pós-guerra, conforme já visto - levaram a uma cultura narcísica. De inspiração psicanalítica, Lasch compreende que, com a perda de credibilidade das autoridades modernas, o superego assume formas infantilizadas, baseadas nas fantasias sádicas sobre os pais, em detrimento da formação do ego que se dá nas experiências posteriores à primeira infância. É, portanto, a partir dessas fantasias, que o indivíduo passa a interagir com a realidade e, por isso mesmo, a sensação é de vazio. É como se ele passasse a buscar em si mesmo os recursos que, de fato, estão na vida social, o que lhe gera “(...) ansiedade, depressão, descontentamento vago, um senso de vazio interno" (Lasch, 1979/1991, p. 13).

O homem apresentado por Lasch busca o prazer obsessivamente, mas tende sempre à frustração, pois o faz calcado em fantasias primárias. Assim, ocorre uma reprodução mecanizada da cultura, com uma proliferação audiovisual da sociedade daquele tempo (e da atual), de tal maneira que se prejudica o próprio senso de realidade do indivíduo (Lasch, 1979/1991). Para Lasch, cabia ao terapeuta, figura que, conforme se verá mais à frente, ganhou imensa notoriedade nos pós-guerra dos EUA, e não ao padre ou outra figura tradicional, cuidar do vazio existencial deste indivíduo, que a ele recorre “(...) na esperança de alcançar o equivalente moderno da salvação, saúde mental” (1979/1991, p. 13, tradução nossa). Isto tornava a terapia uma antirreligião, não pelo uso de métodos científicos ou explicações do plano da racionalidade, senão que por sua ênfase no agora. Esta ênfase, segundo Lasch (1979/1991), evidenciava a falta de futuro da sociedade que, assim, “(...) não se importa com nada além de suas necessidades imediatas. Mesmo quando terapeutas falam de necessidade de 'significado' e 'amor', definem amor e significado como o preenchimento das necessidades emocionais do paciente" (p. 13, tradução nossa). A crítica elaborada por Lasch, como se pode perceber, gira em torno da ideia de um indivíduo pouco afeito ao encontro com a alteridade, mesmo que esteja com outras pessoas, e de uma psicologia que mantém estas ilusões.

O contexto descrito acima incidiu diretamente sobre os rumos adotados pela Psicologia estadunidense. Afinal, a convivência entre guerra, prosperidade, contestação e conservadorismo criou novas demandas para o entendimento e o acolhimento da experiência humana. O significado do que é propriamente humano passou a ocupar debates e a Psicologia não fugiu desse clamor. Neste sentido, a seguir, será feita uma discussão sobre de que modo os acontecimentos acima possibilitaram a Rogers conquistar um espaço até então inédito para a Psicologia aplicada, especialmente nos campos da psicoterapia e do aconselhamento psicológico. Posteriormente, como consequência de todo o contexto, serão apontadas três grandes questões a que o pensamento de Rogers estava atrelado em seu desenvolvimento, a saber, a autenticidade no âmbito das relações humanas, o questionamento de um modelo tecnocrático de produção de conhecimento em Psicologia e, por fim, o risco que a revolução interior proposta pela contracultura e abraçada pela psicologia humanista tinha de se tornar uma forma de narcisismo nos termos discutidos por Lasch (1979/1991).

\section{A Gestação do Pensamento Rogeriano no Cenário do Pós-guerra Estadunidense}

A Psicologia foi uma das profissões que mais passaram por transformações a partir do que 
houve nos EUA, seja quanto a uma redefinição de seus interesses teóricos, seja na própria identidade da profissão. Essas mudanças seguramente foram cruciais para que Rogers e todos os outros chamados "humanistas" desenvolvessem seus trabalhos. Até a Segunda Guerra Mundial, a Psicologia nos EUA valorizava demasiadamente as atividades de laboratório (Grogran, 2008), a ponto de Capshew (1999) identificar que esse tipo de trabalho tinha uma função quase religiosa, e com grande prevalência de uma perspectiva behaviorista. Por isso, a maioria dos psicólogos tinha a docência como atividade e a Psicologia Clínica era vista como algo menor, incapaz de ser investigada nos moldes científicos e praticada por mulheres, que ganhavam menos do que homens com titulação equivalente. A tensão entre o aspecto científico e a atividade profissional naquele país pendia fortemente para aquele vinculado a mensuração, previsão e controle.

A contribuição de psicólogos em várias atividades durante a Segunda Guerra Mundial foi decisiva para uma mudança que se consolidaria a partir dos anos 1960. Essa transformação tem como foco a legitimidade de uma Psicologia aplicada a situações e contextos cotidianos, não restrita ao âmbito dos laboratórios. Para Grogan (2008), a tensão entre ciência e profissão presente no referido contexto era reflexo do embate entre visões atomistas e holísticas quanto ao objeto sobre o qual se debruçava a Psicologia. Foi, portanto, o segundo grande conflito bélico mundial que forçou os acadêmicos a tentarem produzir respostas para as questões consideradas de maior relevância social. Em 1939, logo após a guerra ser iniciada, a American Psychological Association (APA) e a American Association for Applied Psychology (AAAP) formaram um comitê consultivo unificado cuja função era informar aos psicólogos a respeito de oportunidades em agências civis e militares durante o período do conflito. Havia um entendimento de que os recursos militares eram divididos em mecânico e humano, de modo que caberia à Psicologia cuidar do último, o que levaria a Robert Yerkes, um dos responsáveis junto ao National Research Council (NRC) para a atuação dos psicólogos nas instituições militares, a defender a ideia de que a Psicologia atuaria como uma engenharia mental (Capshew, 1999), cujo foco era o aperfeiçoamento da adaptação de pessoas.

A aplicação de testes para a seleção de pessoal era a atividade que tinha mais destaque. Além disso, as atividades dos psicólogos, todas dizendo respeito ao fator humano do âmbito militar, eram “(...) visão, controle de tiro, comunicações, seleção e treinamento” (Capshew, 1999, p. 146, tradução nossa). Skinner, cujas pesquisas envolviam o uso de pombos para guiar mísseis em combate, era exceção. Todas essas atividades envolviam desenvolvimento e aplicação de pesquisas, o que, na prática, significou o fim das fronteiras estabelecidas entre teoria e prática (Capshew, 1999)

Com a maior evidência de atividades práticas, foram privilegiadas pelos fundos governamentais para pesquisa as áreas “(...) clínica, aconselhamento, educacional e industrial/ organizacional” (Pickren, 2007, p. 280). A clínica, portanto, atividade marginal antes do início do conflito, passou a ganhar importância, embora ainda ficasse inicialmente restrita à aplicação e interpretação de testes (Grogan, 2008). Somente em 1941, um grupo de trabalho do qual Rogers fazia parte organizou uma conferência para discutir a formação de psicólogos clínicos e definiu a atividade da Psicologia Clínica como “(...) a técnica e a arte de aplicar princípios psicológicos aos problemas da pessoa individual visando proporcionar-lhe um ajustamento mais satisfatório" (Rogers, 1941 citado em Capshew, 1999, p. 135).

Para Grogan (2008), financiamento de pesquisas, crescimento populacional, urbanização, expansão do ensino superior e escassez de outros profissionais, especialmente psiquiatras contribuíram para a expansão na Psicologia nos EUA durante o pós-guerra. Especialmente, o financiamento de pesquisas através dos fundos Veterans Administration e Public Health Service foi decisivo nesse processo. Para Kirschenbaum (2007), o crescimento da psicologia clínica àquela época se deve ao reconhecimento da necessidade de profissionais de saúde mental, por conta da Segunda Guerra Mundial, da demanda por um trabalho clínico pedido pela Associação de Veteranos de Guerra (Veterans Administration), da expansão de planos de saúde como um benefício trabalhista e do estabelecimento do National Institut of Mental Health. Assim, a Psicologia Clínica passou a ocupar espaços em programas de graduação e pósgraduação nos EUA.

Isso coincide exatamente com o período em que Rogers começou a desenvolver seu trabalho autoral de forma mais consistente. Em 1942, havia lançado Counseling and Psychotherapy, que, embora não tenha sido recebido entusiasticamente pela academia, teve boa circulação diante da crescente demanda por trabalhos que envolvessem intervenção terapêutica impulsionada pelo retorno dos veteranos de guerra (Rogers \& Russell, 2002).

Durante a guerra, Rogers havia participado de vários grupos de trabalho para definir a atuação do psicólogo, trabalhando para agências civis e militares, além de ter suas técnicas de entrevista (até então denominadas de aconselhamento nãodiretivo) amplamente utilizadas. Segundo De Carvalho (1999), a terapia desenvolvida por Rogers foi amplamente utilizada por ser “(...) simples, informal, breve e requerer pouco treinamento" (p. 142, tradução nossa). Rogers foi contratado para dar cursos breves sobre como trabalhar com os veteranos que voltaram da guerra a partir de sua recém-criada terapia não-diretiva e lançou um manual sobre a temática (Rogers \& Wallen, 1946/2000).

Essa ascensão fez com que Rogers fosse convidado a assumir um cargo de professor na Universidade de Chicago, onde a promessa de coordenação de um centro de aconselhamento e de uma máquina mais moderna para gravar as entrevistas foi decisiva para sua mudança. Rogers foi o primeiro a gravar sessões de psicoterapia para posterior e incansável análise com seus estudantes 
e parceiros. Suas primeiras gravações, porém, ocorriam muito precariamente, com a utilização de discos que precisavam ser trocados a cada 3 minutos. Isso não impediu que ele publicasse, em 1942, o caso Bryan, primeiro transcrito e publicado integralmente (Rogers \& Russell, 2002).

Gradativamente, a Psicologia Clínica avançou de um lugar reduzido à interpretação de testes à possibilidade de intervenção vinculada à ideia de adaptação demandada durante o conflito. Não por acaso, em 1946, Rogers, cujas pesquisas se concentravam no âmbito da Psicologia Clínica, foi eleito presidente da APA (Capshew, 1999).

Embora a clínica conquistasse um espaço cada vez mais significativo, as pesquisas em Psicologia da década de 1950 tinham uma faceta nomotética e quantificadora, ou seja, era preciso estabelecer leis gerais e replicáveis para um determinado fenômeno a partir de alguma medida que pudesse indicá-lo (Capshew, 1999). Mesmo pesquisas vinculadas à Psicologia Clínica, como as realizadas por Rogers, tinham essa marca. Não era incomum encontrar entre os escritos do Rogers medidas estatísticas que tentassem validar aquilo que ele tentava provar através da psicoterapia (Rogers, 1951/1975, 1957/1992; 1961/2001a; Rogers \& Dymond, 1954). A tecnocracia que, conforme já se viu, foi um forte traço dos EUA pós-guerra atingia diversos âmbitos - inclusive o da pesquisa em Psicologia Clínica.

Para compreender especificamente o lugar de Rogers na discussão entre clínica e pesquisa, é preciso tomar como referência seu contexto, qual seja o fato de que a pesquisa em Psicologia nos EUA só se justificava a partir de um compromisso com o método científico extraído da lógica laboratorial. Rogers, inclusive, é extremamente reconhecido como aquele que tirou a psicoterapia de uma dimensão privada, quanto à análise de seu conteúdo, para a esfera pública da investigação científica e, certamente, deve isso a uma formação que valorizava exclusivamente aquilo que poderia ser demonstrado e quantificado em pesquisa (Rogers \& Russell, 2002; Kirschenbaum, 2007). Ocorre que, conforme se verá adiante, a ciência, pelo menos no período em que Rogers produziu, não abria espaço para a liberdade e a genuinidade, ou seja, para a possibilidade de que a fruição da experiência não tivesse parâmetros enrijecidos por métodos a serem reproduzidos.

É exatamente contra formas tecnocráticas de se fazer Psicologia que, no início dos anos 1960, se insurge a Psicologia Humanista (Rogers \& Russell, 2002). De acordo com Grogan (2008), questões como a identidade diante de um mundo capitalista e, como eram os EUA, próspero, bem como a definição de saúde mental para além da doença, foram fundamentais para o humanismo. O momento de emergência das ideias humanistas na Psicologia era exatamente aquele em que alguns estadunidenses estavam se perguntando sobre seus valores e questionando o modelo de sociedade em viviam. Contribuíram significativamente para estes questionamentos as reflexões de psicanalistas neofreudianos, como Karen Horney, Erich Fromm e Harry Sullivan, que criticavam o modelo de desenvolvimento humano para o qual a financeiramente próspera sociedade estadunidense caminhava (Castelo Branco, Vieira, Cirino \& Moreira, 2016; Grogan, 2012).

Rogers, que certamente se identificava com a ideia de dar um novo significado à ciência psicológica, ocupava uma posição ambígua no chamado movimento humanista, tentando conciliar a tradição do método experimental às propostas daquele movimento (Vieira, 2017). Se, por um lado, se reconhecia como um teórico cujas contribuições eram limitadas às técnicas que havia criado, portanto fora do mundo acadêmico (Rogers, 1974), por outro nutria verdadeira paixão pelo método científico (Rogers \& Coulson, 1968/1973). Para Grogan (2012), o contexto de questionamento dos anos 1960, que prenunciava uma série de mudanças na cultura estadunidense, alimentou o ímpeto dos psicólogos humanistas, entre eles Rogers, em seu âmbito de atuação. Suas ideias se espalharam velozmente pelos EUA e passaram a ganhar destaque tanto no âmbito acadêmico quanto no profissional.

Uma das manifestações culturais que mais se identificaram com a Psicologia Humanista foi a contracultura, materializada a partir do Movimento do Potencial Humano (Human Potential Movement), que se valeu “(...) das mais diversificadas técnicas grupais, corporais, bioenergéticas, de massagens, da filosofia oriental, etc" (Campos, 2006, p. 251) para a promoção do potencial humano diante de uma sociedade vista como opressora. Segundo Campos (2006), vigorava neste movimento a filosofia do drop out, ou seja, cair fora do sistema político e social, bem como do predomínio da racionalidade científica.

Nesse contexto, no final de 1963, Rogers deixou a Universidade Wisconsin para se aposentar da vida acadêmica e se dedicar a atividades ligadas a trabalhos com grupos, no Western Behavioral Science Institute (WBSI). Juntamente com a Universidade, Rogers deixou de fazer psicoterapia individual, e passou a se dedicar intensamente a trabalhos com grupos (Rogers \& Russell, 2002; Kirschenbaum, 2007). Na avaliação de Grogan (2008), houve, certamente, um desequilíbrio entre a dimensão experiencial do conhecimento (sobretudo do autoconhecimento) e a exploração intelectual de suas implicações. Mesmo uma ferramenta acadêmica como Journal of humanistic Psychology se tornou algo próximo disso, ao reproduzir os defeitos do movimento. Em entrevista a Grogan (2008), Richard Farson, um dos diretores do WBSI, onde Rogers trabalhou durante 4 anos, diz que, em nome da tentativa de não adotar uma perspectiva reducionista sobre o humano (como os humanistas acreditavam que faziam a psicanálise e o behaviorismo), os humanistas foram ao outro extremo, reduzindo-o a sentimentos, emoções e escassa reflexão.

Apesar de uma marcante influência nos vários campos de atuação do psicólogo especialmente na clínica - não é difícil encontrar 
textos discutindo os motivos de um declínio do humanismo a partir da segunda metade dos anos 1970 e, até mesmo, a viabilidade de sua sobrevivência no cenário contemporâneo (Cain, 2003; Serlin, 2011). Para Grogran (2012), a falta de credibilidade acadêmica, somada ao conservadorismo que se aprofundou nos EUA a partir dos anos 1970, fez com que o interesse pela Psicologia Humanista se reduzisse progressivamente. Afinal, filosoficamente, a Psicologia Humanista punha em xeque muitas relações de poder estabelecidas em nosso cotidiano, como entre professor e aluno, e terapeuta e cliente (Rogers, 1977/2001b), se apresentando como um risco aos defensores do status quo. Outro fator que contribuiu para a decadência do humanismo nos EUA foi o afastamento que o movimento produziu em relação à academia. Rogers via isto com preocupação: “(...) a Psicologia Humanista não está bem representada nos cursos das grandes universidades. Se a Psicologia Humanista tiver que ter um futuro maior terá que de alguma forma penetrar nas universidades mais profundamente. Terá que encontrar caminhos para fazer pesquisa" (Rogers \& Russell, 2002, p. 304, tradução nossa).

No cenário delineado, portanto, na virada dos anos 1970 para a década posterior, o humanismo não tinha mais a mesma relevância de 20 anos antes. Na avaliação de Grogan (2012), era como se o contexto indicasse que a Psicologia Humanista havia falhado em suas promessas, pois, na década de 1980, 45\% dos americanos sentia que a vida havia piorado, já que conviviam com estagnação econômica, aumento de índices de criminalidade, além de crise energética. Grogan avalia que Rogers encontrava uma receptividade maior fora de seu país do que lá. Foi neste período, aliás, que Rogers veio ao Brasil (Rogers, 1980/1983).

Como se pode perceber, há uma interseção entre a cultura e o desenvolvimento da Psicologia nos EUA no que tange às questões que marcaram aquele país entre as décadas de 1940 e 1970. Os questionamentos que rondavam o período em questão, portanto, podem ser elencados para nos dar mais ferramentas no intuito de compreender em que lugar o pensamento de Rogers se produzia. Não pretendemos com eles totalizar o período discutido, mas apontar tendências e caminhos que, mesmo à revelia da vontade de Rogers, estavam presentes em sua época e lugar.

\section{A Autenticidade e a Busca por Tornar-se uma Pessoa}

Um tema emergente a partir das discussões acima é o da autenticidade. Num período em que a desconfiança e a tarefa de aparentar ser de uma forma que pudesse ser aceita por um determinado grupo dominavam as relações, as possibilidades de uma expressão autêntica estavam na pauta do dia. Quais os espaços para se expor sem desconfiança numa cultura assim? Uma psicologia que não tivesse a adaptação como meta de seu trabalho, mas que se preocupasse com a singularidade da experiência humana ia fortemente de encontro ao pensamento conservador vigente e ao encontro de anseios emergentes nos movimentos contestatórios discutidos acima. Para Rogers (Rogers \& Kinget, 1962/1977), a gênese do sofrimento humano reside no desenvolvimento da necessidade de sentir-se aceito por outros significativos, por ele denominados pessoas-critério, na medida em que isto entraria em contradição com as necessidades organísmicas do indivíduo.

No pensamento clínico de Rogers, portanto, ser pessoa significa afirmar-se como singularidade diante do mundo. A busca humana primordial, para Rogers (1961/2001a), é a de entrar em contato com questões existenciais como o sentido da vida, a liberdade, entre outras, o que, em Riesman (1950/1971), pode ser entendido através do drama da multidão solitária. Nesse sentido, a emergência dessa autenticidade se dá na medida em que o terapeuta oferece uma relação cuja premissa básica é de confiança e de acolhimento da diferença e na qual se afirma como pessoa genuinamente interessada na compreensão da experiência do outro.

A partir de suas observações clínicas, Rogers (1961/2001a) conclui que, quando o cliente é livre para escolher, opta por confiar num processo de abertura à experiência presente, em vez de ceder à necessidade de cumprir com a expectativa alheia - o que ele chama, inspirado por Kierkegaard, de tornarse o que se é (Pinheiro \& Vieira, 2011). Ser uma pessoa, portanto, implica em algo muito próximo do que Riesman visualizava como saída para a personalidade alterdigirida, ou seja, a necessidade de maior autoconsciência e reconhecimento das emoções e limitações de cada um perante as demandas por aderir passivamente ao coletivo. Nem Rogers, nem Riesman, apostam que daí resultaria algum tipo de atitude individualista, pois creem numa convivência em que se afirmam as diferenças, num processo de recíproco e contínuo de abertura à alteridade, o que não necessariamente é verdadeiro (Vieira \& Freire, 2006; Vieira \& Pinheiro, 2015).

\section{O Pensamento Tecnocrático em Questão}

O questionamento da tecnocracia como modo de validação do conhecimento, ainda que ambiguamente, é outra marca profunda da obra rogeriana. Rogers, desde muito cedo, desenvolve uma concepção de aconselhamento que desafia a ideia de que o terapeuta precisa ser um especialista sobre a personalidade humana, ou ter uma aguçada habilidade psicodiagnóstica (Rogers \& Wallen, 1946/2000). Coloca em xeque a autoridade do terapeuta como um técnico e o apresenta como uma pessoa interessada em outra. Longe, portanto de um tecnocrata, o terapeuta se apresentava como alguém para quem, no momento imediato do encontro com o outro, a teoria era nociva.

Para Rogers (1961/2001a), os lugares ocupados por terapeuta e cientista são deveras distintos e, mesmo quando tenta pô-los em diálogo, 
o faz de modo a dizer de um através da realidade do outro. Dito de outra forma: se o cientista é o que observa, analisa e extrai uma forma de funcionamento da relação, e o terapeuta tem como tarefa se entregar ao encontro interessado diante do outro, o único diálogo possível entre eles é através de uma redefinição de ciência. Isso ocorre na medida em que Rogers tenta pensar a ciência como atividade que envolve escolha de valores, seja a partir do tema que o cientista escolhe, ou dos métodos que utiliza em sua pesquisa. Rogers se viu às voltas com um forte embate entre sua formação acadêmica de pesquisador e a descoberta de uma liberdade no encontro com o outro que não tinha lugar na ciência.

Podemos dizer que o questionamento sobre a tecnocracia no pensamento rogeriano se faz presente também na discussão sobre o sentido de uma vida boa (Rogers, 1961/2001a; Vieira \& Freire, 2012). Isto está em consonância com o movimento dos direitos civis e a nova esquerda que, embora tivessem como objetivo demandas coletivas, enfocavam o valor do indivíduo ou, ainda, a libertação do eu (self). Tal questão que, de acordo com Grogan (2012), esteve presente em vários debates da democracia americana. Esta visão também é compartilhada por Campos (2006) que vê a Psicologia Humanista em sintonia com as mudanças que se apresentavam na cultura americana. Rogers também se pergunta sobre que modelo de vida a Psicologia ajuda a construir e afirma, num claro embate com Skinner, que o que faz a vida ser boa não é a possibilidade de ser controlado pelo outro, mas a liberdade (Rogers, 1961/2001).

Mesmo sendo um assumido admirador do método científico (Rogers \& Coulson, 1968/1973; Rogers \& Russell, 2002; Kirschenbaum, 2007), Rogers não deixava de se questionar quanto aos impasses éticos que seu trabalho envolvia. A teoria que desenvolveu é toda voltada para a afirmação do valor da pessoa, e toma este valor, inclusive, como algo decisivo não apenas no plano da construção teórica, mas na experiência, de modo pré-reflexivo. Toda a atuação do terapeuta gira em torno da afirmação dessa ideia em suas atitudes, de tal forma que isto é comunicado e sentido na interação.

\section{Narcisismo e a Busca da Compreensão de si}

Se havia a necessidade de um saber engajado e um questionamento sobre o sentido de uma ciência humana, a busca por uma compreensão de si por vezes tendia a reforçar uma cultura narcísica e, portanto, pouco preocupada com o que ocorria ao redor. A linha entre autodescoberta e narcisismo era bastante tênue e sua tensão atravessava (e atravessa até hoje) todos os saberes e práticas psicológicas. Havia, e por vezes ainda há, o iminente risco de que a necessidade de mudança psíquica que tomou o lugar da mudança da estrutura social na contracultura (Roszak, 1968/1972) pudesse significar aniquilamento da convivência em sociedade. Ou ainda, de que coletivos se resumissem a espaços protegidos, com duração limitada e artificial como os grupos de encontro, numa realização quase profética do que Lasch identificou como cultura do narcisismo.

Rogers via nos grupos uma possibilidade de mudança que se expandiria para dimensões além do momento presente. Suas tentativas de mediação de conflitos entre grupos historicamente rivais (Rogers, 1977/2001b; Rogers \& Russell, 2002) evidenciam uma constante preocupação de que seu trabalho pudesse contribuir para a paz mundial, por exemplo. Para Rogers, os grupos eram uma ferramenta que poderia levar a uma melhor convivência coletiva (Farson,1979). Não por acaso, Figueiredo (1991), ao tentar delinear o lugar epistemológico que ocupa a Psicologia Humanista no que ele chama de Matrizes do Pensamento Psicológico, compara-a a seitas em que a linguagem e o abandono da linguagem verbal bastariam para uma relação genuína com o mundo. Neste sentido, o autor referido aponta para o perigo ideológico do ideário humanista de afirmar uma liberdade irrefletida, incapaz de pensar os condicionantes que a impedem de ocorrer. Outra crítica relevante é feita por May (1982/1989) quando coloca a Rogers o problema do mal. Nela, o autor aponta uma unidimensionalidade da experiência humana nas ideias do criador da ACP ao sobrevalorizar uma dimensão positiva da natureza humana (Rogers, 1957/2014) que por vezes ignora o seu avesso. Quando Rogers raciocina assim, atribui à cultura o corrompimento dessa natureza positiva e, desta forma, ignora que os processos culturais são criações humanas. Nesse sentido, deixaria de reconhecer uma dimensão de historicidade na experiência do sujeito, uma vez que isto o lançaria num campo de solipsismo cuja fonte para o desenvolvimento seria uma bagagem natural garantida na filogênese.

Grogan (2008), por sua vez, associa os grupos de encontro ao individualismo americano. A transformação de si, portanto, em muitos momentos, suplantou qualquer sonho de mudança do mundo concreto e diminuiu a virulência crítica que o movimento poderia ter. $\mathrm{O}$ que se viu após o movimento dos grupos de encontro e das reflexões de Lasch foi um aprofundamento de uma cultura narcísica e, portanto, com pouco espaço para uma convivência com a alteridade - o que é bem distinto da tolerância. Ao que parece, a despeito das aspirações rogerianas, seu escopo teórico não foi capaz de prever este desdobramento.

\section{Considerações Finais}

Abordamos neste trabalho as condições de possibilidade para a gestação do pensamento de Rogers. Como se pôde ver, o contexto da segunda grande guerra produziu uma série de modificações na sociedade estadunidense, como prosperidade, protestos de populações marginalizadas e focos de conservadorismo convivendo num mesmo território em diferentes décadas. Vale dizer que a separação por décadas é mais didática do que 
real, visto que é impossível delimitar exatamente em que momento cada movimento se inicia e se finda. O que interessa de fato é que a relação entre todos esses acontecimentos criou condições para que Rogers, entre outros pensadores da Psicologia Humanista, atentasse para um novo modo de fazer Psicologia.

Tais condições estavam associadas, dentre outros, ao fato de a Psicologia fora do laboratório, tida como um campo de segunda categoria, ter conquistado um novo patamar a partir da atuação junto aos veteranos de guerra, impulsionada pela necessidade do desenvolvimento de um método simples e prático que pudesse amenizar seu sofrimento. Destacou-se, ainda, o financiamento de pesquisas por parte do fundo estatal dos veteranos de guerra que patrocinou novas iniciativas neste sentido. Por outro lado, num contexto em que a desconfiança dava o tom dos modos de vinculação e cuja realização pessoal estava ligada a ideias de consumo e aceitação pelo grupo, tal Psicologia, em resposta ao sofrimento derivado da forma de organização vigente, se propôs a pensar no que significa ser uma pessoa imersa em relações abertas e genuínas. Essa temática ganha força quando se alia a um questionamento sobre uma idolatria em torno de maneiras tecnocrática de compreensão do real.

Desta forma, parece-nos evidente que a produção do pensamento de Rogers não se deu apenas pela influência deste autor por outros pensadores de seu tempo. No que pese a importância de várias reflexões em seu contexto, interessounos entender algumas das perguntas a que Rogers respondia e de que modo isso ocorreu, bem como os riscos implicados neste processo. Vale dizer que o exercício aqui proposto não se encerra em si, tampouco tem a pretensão de passar a limpo todo o contexto em que a produção rogeriana se deu, dados os limites que ele possui. Não foram abordados, por exemplo, elementos de sua biografia pessoal ou acadêmica, visto que nos interessava mais um panorama cultural geral que nos permitisse uma compreensão das condições de possibilidade de gestação do pensamento em tela. Tampouco se discutiu sua relação com outros pensamentos da Psicologia Humanista, que, a seu modo, respondiam a questões semelhantes às suas, pois entendemos que, se assim fizéssemos, poderíamos abordar a questão por um prisma mais epistemológico do que cultural. Esperamos, contudo, que o texto possa cumprir sua missão de provocar novas reflexões em torno daquilo que produziu uma obra tão profícua quanto o de Rogers.

\section{Referências}

Brownell, R. (2011). American counterculture of the 1960s. New York: Lucent Books.

Cain, D. J. (2003). Advancing humanistic psychology and psychotherapy: some challenges and proposed solutions. Journal of Humanistic Psychology, 43 (3), 10-41. DOI: 10.1177/0022167803254120.
Campos, R. F. (2006). Os anos 60 e o projeto de Psicologia Humanista. Epistemo-Somática (Belo Horizonte), 3 (2), set/dez, 242-260.

Capshew, J. H. (1999). Psychologists on the march: Science, practice, and professional identity in America, 1929-1969. New York: Cambridge University Press.

Castelo Branco, P. C. (2010). A noção de organismo no fieri teórico de Carl Rogers: uma investigação epistemológica. Dissertação de Mestrado em Psicologia. Programa de Pós-Graduação em Psicologia da Universidade Federal do Ceará, Fortaleza, Brasil.

Castelo Branco, P. C., Vieira, E. M., Cirino S. D. \& Moreira, J. O. (2016). Influências da Psicanálise neofreudiana na psicoterapia de Carl Rogers. Contextos clínicos, 9 (2), 279-289. DOI: 10.4013/ctc.2016.92.12.

Cury, V. E. (1987). Psicoterapia centrada na pessoa: evolução das formulações sobre a relação terapeuta-cliente. Dissertação de Mestrado em Psicologia. Programa de Pós-Graduação em Psicologia Clínica, Universidade de São Paulo, São Paulo, Brasil.

De Carvalho, R. J. (1999). Otto Rank, the rankian circle in Philadelphia, and the origins of Carl Rogers' person-centered psychotherapy. History of Psychology, 2 (2), 132-148. DOI: 10.1037/1093-4510.2.2.132.

Farber, D. \& Bailey, B. (2001). The Columbia guide to America in the 1960s. New York: Columbia University Press.

Farson, R. (1979). Carl Rogers, revolucionário tranquilo. Em R. I. Evans. Carl Rogers: o homem e suas ideias (pp. 25-36). São Paulo: Martins Fontes.

Figueiredo, L. C. M. (1991). Matrizes do pensamento psicológico. Petrópolis: Vozes.

Figueiredo, L. C. M. (1992). A invenção do psicológico: quatro séculos de subjetivação - 1500 -1900. São Paulo: Escuta.

Foertsch, J. (2008). American Culture in the 1940s. Edinburgh: Edinburgh University Press.

Gair, C. (2007). The american counterculture. Edinburgh: Edinburgh University Press.

Grogan, J. L. (2008). A cultural history of the humanistic psychology movement in America. Tese de doutorado em Psicologia. Graduate School of The University of Texas, Austin, EUA.

Grogan, J. (2012). Encountering America: humanistic psychology, sixties culture $\&$ the shaping of the modern self. New York: Harper Perennial.

Halliwell, M. (2007). American Culture in the 1950 s. Edinburgh: Edinburgh University Press.

Hobsbawm, E. (2004). A era dos extremos: o breve século XX: 1914-1991. São Paulo: Companhia das Letras. (Originalmente publicado em 1994).

Kirschenbaum, H. (2007). The life and work of Carl Rogers. Ross-on-Wye, England: PCCS Books. 
Kaufman, W. (2009). American Culture in the 1970 s. Edinburgh: Edinburgh University Press.

Lasch, C. (1991). The culture of narcissism. New York: W. W. Norton. (Originalmente publicado em 1979).

May, R. (1989). The problem of evil: an open letter to Carl Rogers. Em H. Kirschenbaum \& V. L. Henderson (Eds.). Carl Rogers dialogues (pp. 239-251). London: Constable (Originalmente publicado em 1982).

Monteith, S. (2008). American Culture in the 1960s. Edinburgh: Edinburgh University Press.

Moreira, V. (2010). Revisitando as fases da abordagem centrada na pessoa. Estudos de Psicologia (Campinas), 27 (4), 537-544. DOI: 10.1590/S0103166X2010000400011.

Pickren, W. (2007). Tension and opportunity in post-world war II American Psychology. History of Psychology, 10 (3), 279-299. DOI: 10.1037/1093.4510.10.3.279.

Pinheiro, F. P. H. A. \& Vieira, E. M. (2011). Convergências entre a Abordagem Centrada na Pessoa e Sören Kierkegaard. Psicologia Argumento, 29 (65), 167-177. Recuperado em 10 de janeiro de 2015 em http://www2.pucpr.br/reol/pb/index.php/pa?d$\mathrm{d} 1=4596 \& \mathrm{dd} 99=$ view $\& \mathrm{dd} 98=\mathrm{pb}$.

Riesman, D. (1971). A multidão solitária: um estudo da mudança do caráter americano. São Paulo: Perspectiva. (Originalmente publicado em 1950).

Rogers, C. R. (1974). In retrospect: Forty-Six years. American Psychologist, 29 (2), 115-123. DOI: 10.1037/ h0035840.

Rogers, C. R. (1975). Terapia Centrada no Cliente. São Paulo: Martins Fontes. (Originalmente publicado em 1951).

Rogers, C. R. (1983). Um jeito de ser. São Paulo: E.P.U (Originalmente publicado em 1980).

Rogers, C. R. (1992). The necessary and sufficient conditions of therapeutic personality change. Journal of consulting and clinical psychology, 60 (6), 827-832. (Originalmente publicado em 1957).

Rogers, C. R. (2001a). Tornar-se pessoa. São Paulo: Martins Fontes. (Originalmente publicado em 1961).

Rogers, C. R. (2001b). Sobre o poder pessoal. São Paulo: Martins Fontes. (Originalmente publicado em 1977).

Rogers, C. R. \& Coulson, W. (1973). O homem e a ciência do homem. Belo Horizonte: Interlivros. (Originalmente publicado em 1968).

Rogers, C. R. \& Dymond, R. F. (Orgs.) (1954). Psychotherapy and personality change. University of Chicago Press.

Rogers, C. R. \& Kinget, G. M. (1977). Psicoterapia e relações humanas (Vol 1). Belo Horizonte: Interlivros. (Originalmente publicado em 1962)
Rogers, C. R. \& Russell, D. (2002) Carl Rogers: the quiet revolutionary - an oral history. Roseville, CA: Penmarin Books.

Rogers, C. R. \& Wallen, M. A. (2000). Manual de counselling. Lisboa: Encontro Editora. (Originalmente publicado em 1946).

Roszak, T. (1972). A contracultura: reflexões sobre a sociedade tecnocrática e a oposição juvenil. Petrópolis: Vozes. (Originalmente publicado em 1968).

Serlin, I. (2011). The history and future of Humanistic Psychology. Journal of Humanistic Psychology, 51 (4), 428-431. DOI: 10.1177/0022167811412.

Suri, J. (2009). The rise and fall of an international counterculture, 1960-1975. The American Historical Review, 114 (1), 45-68. Retirado em 12 de fevereiro de 2015 em: http://www.jstor.org/stable/30223643.

Vieira, E. M (2017). Ética e psicologia: uma investigação sobre os ethoi da terapia centrada na pessoa. Tese de Doutorado em Psicologia. Programa de pós-graduação em Psicologia. Belo Horizonte: Universidade Federal de Minas Gerais.

Vieira, E. M., \& Freire, J. C. (2006). Alteridade e psicologia humanista: Uma leitura ética da abordagem centrada na pessoa. Estudos de psicologia (Campinas), 23 (4), 425-432.

Vieira, E. M. \& Freire, J. C. (2012). Psicopatologia e Terapia Centrada no Cliente: por uma clínica das paixões. Memorandum, 23, 57-69.

Vieira, E. M. \& Pinheiro, F. P. H. A. (2015). Ethics and the person-centered approach: a dialogue with radical alterity. Theory and Psychology, 25 (6), 798-813. DOI: 10.1177/0959354315591051.

Wanderley, A. R. (1999). Narcisismo contemporâneo: uma abordagem laschiana. Physis: Rev. Saúde Coletiva, 9 (2).

Emanuel Meireles Vieira possui Graduação em Psicologia pela Universidade Federal do Ceará, Mestrado em Psicologia pela mesma Universidade e Doutorado em Psicologia pela Universidade Federal de Minas Gerais Professor Adjunto II da Faculdade de Psicologia da Universidade Federal do Pará (UFPA), onde coordenou o serviço de Plantão Psicológico da Clínica-Escola entre 2010 e 2013. Endereço Institucional: Faculdade de Psicologia, Instituto de Filosofia e Ciências Humanas, Universidade Federal do Pará. Rua Augusto Corrêa, 01, Guamá, Belém - Pará, CEP 66073-040. Email: emanuel.meireles@gmail.com

Francisco Pablo Huascar Aragão Pinheiro é professor do Curso de Psicologia da Universidade Federal do Ceará (Campus de Sobral). Possui Graduação em Psicologia, Mestrado em Psicologia e Doutorado em Educação pela Universidade Federal do Ceará. 
Jacqueline de Oliveira Moreira é Doutora em Psicologia Clínica pela Pontifícia Universidade Católica de São Paulo. Atualmente é Professora Adjunto III da Pontifícia Universidade Católica de Minas Gerais, integrando o corpo docente do mestrado e doutorado em Psicologia. Bolsista Produtividade PQ2 do Cnpq e Pesquisador Mineiro FAPEMIG (2014-2017).

Andréa Maris Campos Guerra possui Graduação em Direito pela Universidade Federal de Juiz de Fora, Graduação em Psicologia pelo Centro de Ensino Superior de Juiz de Fora, Mestrado em Psicologia Social pela Universidade Federal de Minas Gerais e Doutorado em Teoria Psicanalítica pela Universidade Federal do Rio de Janeiro, sendo atualmente Professora Adjunta do Departamento e do Programa de Pós-Graduação em Psicologia da Universidade Federal de Minas Gerais.

Recebido em 12.07.2017

Aceito em 06.11.2017 